Карнаух C. $\Gamma$.

\title{
ЭКСПЕРИМЕНТАЛЬНЫЕ ИССЛЕДОВАНИЯ ПРОЦЕССА РАЗДЕЛЕНИЯ ПРОКАТА ПО СХЕМЕ ТРЕХТОЧЕЧНОЙ ХОЛОДНОЙ ЛОМКИ ИЗГИБОМ ПРИ СТАТИКО-ДИНАМИЧЕСКОМ НАГРУЖЕНИИ
}

Затраты заготовительного производства составляют значительную долю в себестоимости готовой продукции. Поэтому задачи совершенствования технологии и оборудования для реализации разделительных процессов являются актуальными [1-6].

На протяжении многих лет в нашей стране и за рубежом проводились работы по тематике разделения сортового проката (труб) на мерные заготовки. Достигнуты существенные результаты в теории и практике реализации заготовительных процессов $[1,2]$. На основе анализа полученных результатов разработаны перспективные направления совершенствования технологий и оборудования разделительных процессов. Одним из таких направлений является обеспечение благоприятного напряженно-деформированного состояния в зоне разделения за счет создания предварительного статического нагружения перед динамическим нагружением проката. Возможность предварительного статического нагружения в сочетании с высокой скоростью деформирования позволяет создать в прокате схему напряженного состояния, обеспечивающую требуемую геометрическую точность и качество получаемых заготовок.

В работе [7] разработана комплексная математическая модель процесса статикодинамического нагружения образцов по схеме трехточечной холодной ломки изгибом на пресс-молоте с одинаковым направлением деформирующих сил, отличающаяся учетом предварительного статического нагружения и конструктивных особенностей специализированного оборудования - пресс-молота. На основании проведенных расчетов сделаны следующие выводы.

Предварительное статическое нагружение при холодной ломке изгибом с высокими скоростями нагружения позволяет снизить высокочастотные колебания системы «инструмент - образец - опоры», исключить нарушение контакта образца с опорами, понизить пиковые величины сил со стороны бойка и опор.

Наличие статической силы в момент удара обеспечивает определенный исходный уровень растягивающих напряжений в зоне концентратора напряжений, что повышает управляемость трещиной. Предполагается, что разрушающая трещина при этом всегда будет распространяться в области растягивающих напряжений.

При этом, возникающие реактивные силы со стороны опор от действия статической силы, совпадают с направлением инерционных сил половинок образца и дополнительно доламывают образец.

Величина статической силы, необходимая для исключения отрыва образца от опор, зависит от жесткости контакта бабы с промежуточным пуансоном и увеличивается с ростом последней.

Цель работы - экспериментальная проверка адекватности математической модели процесса разделения образцов по схеме трехточечной холодной ломки изгибом при статикодинамическом нагружении и разработка перспективных схем оборудования для реализации этого процесса.

В эксперименте использовались образцы диаметром 20 мм и длиной 100 мм из сталей с разными механическими свойствами: Ст3; 30, 40, 50ХФА. На образцы, предварительно с помощью токарного резца, наносили одинаковые концентраторы напряжений в форме кольцевой канавки с параметрами $\Delta H=1,5 \mathrm{mм} ; r=0,15 \mathrm{Mм}$. 
На рис. 1 приведены: схема регистрации данных при проведении экспериментов (рис. 1, а), конструктивная схема (рис. 1,в), а также фотографии экспериментального оборудования (рис. 1, б) и оснастки (рис. 1, г) [8].

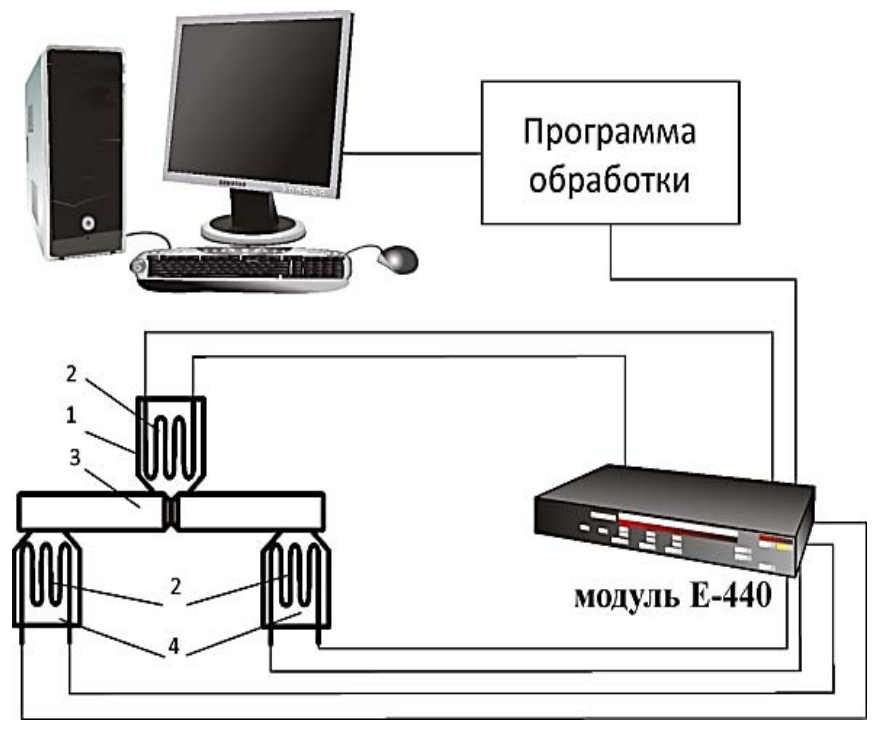

1 - ломатель; 2 - тензодатчики;

3 - образец; 4 - опоры

a
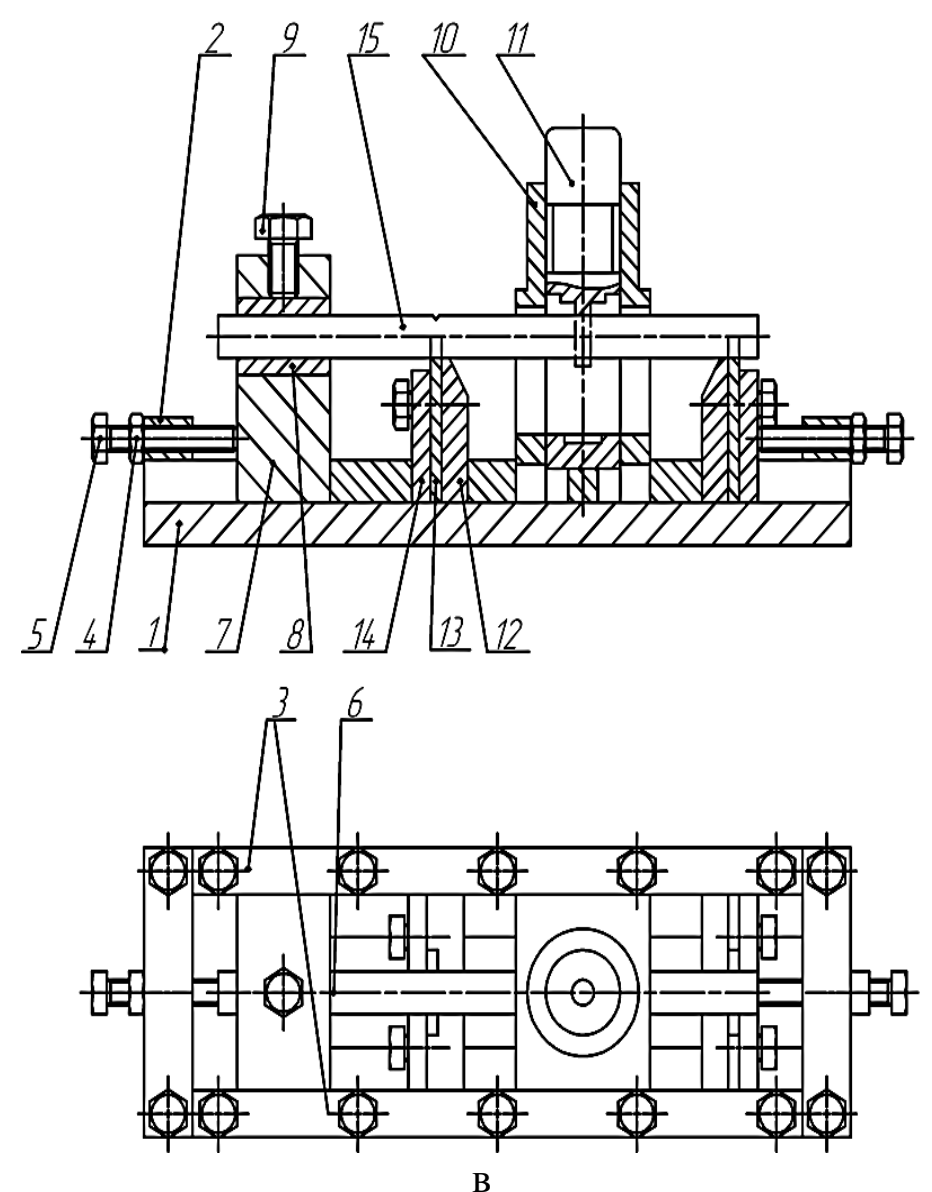

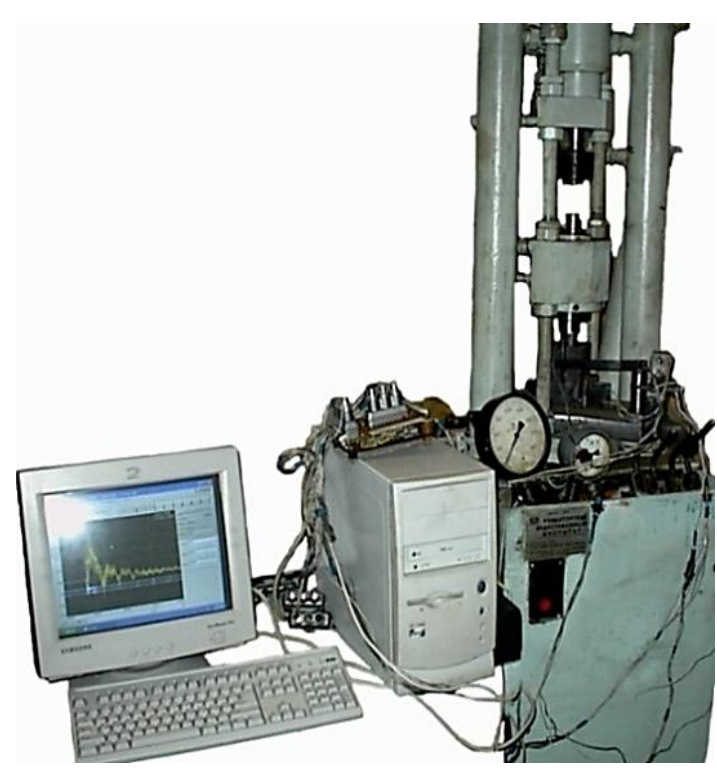

б
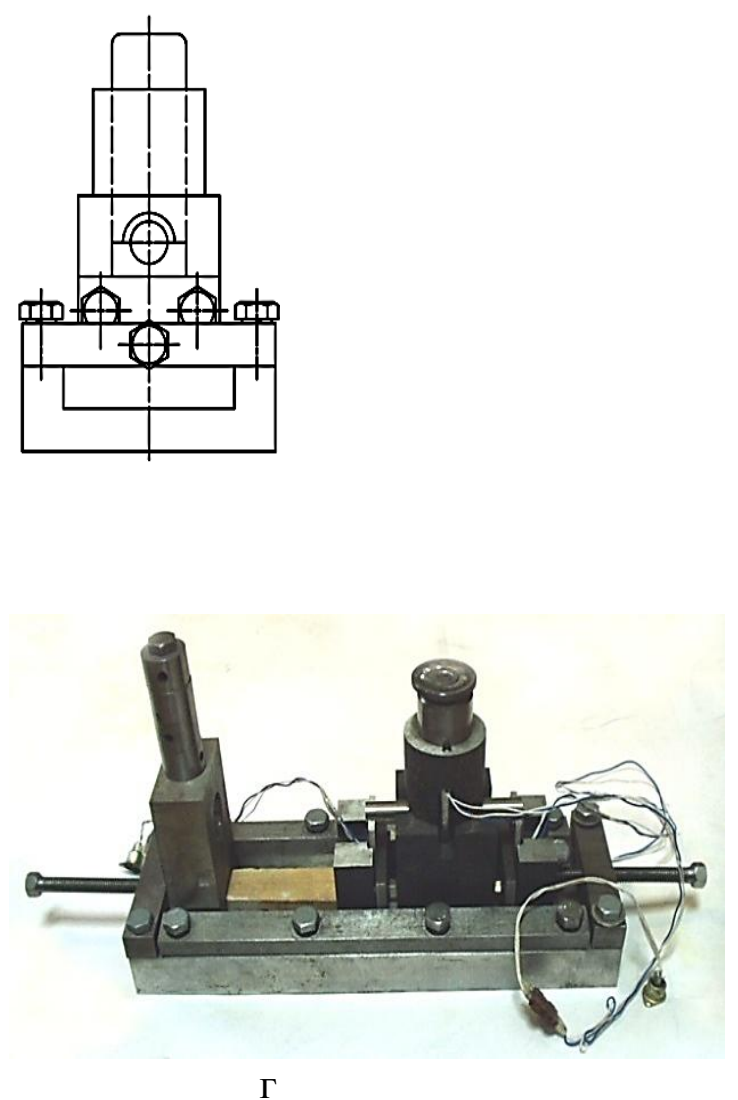

Рис. 1. Схема регистрации экспериментальных данных (а), конструктивная схема (в) и фотографии экспериментального оборудования (б) и оснастки (г) [8] 
Установка для разделения образцов способом холодной ломки изгибом (см. рис. 1, в) состоит из: станины 1, в направляющих которой размещаются механизмы зажима проката, ломателя и опор, установленных с возможностью возвратно-поступательного движения, ограниченного упорами 2 и накладками 3, которые крепятся к станине 1 болтами. Положение механизмов зажима, ломателя и опор фиксируется с помощью болтов 5, вкрученных в упоры 2 , гаек 4 и проставок 6. Механизм зажима проката состоит из корпуса 7, в отверстии которого размещается образец 15 между полувтулками 8, зажимающиеся с помощью болта 9, вкрученного в корпус 7. Механизм ломателя состоит из корпуса 10 и собственно ломателя 11, установленного с возможностью возвратно-поступательного движения в направляющих корпуса. Механизм опоры состоит из корпуса 12 и опорной пластины 13, которая удерживается накладкой 14 с помощью болтов с шайбами.

На рис. 2 показана обработанная осциллограмма энергосиловых параметров процесса трехточечной холодной ломки изгибом от времени для образцов из стали 45.

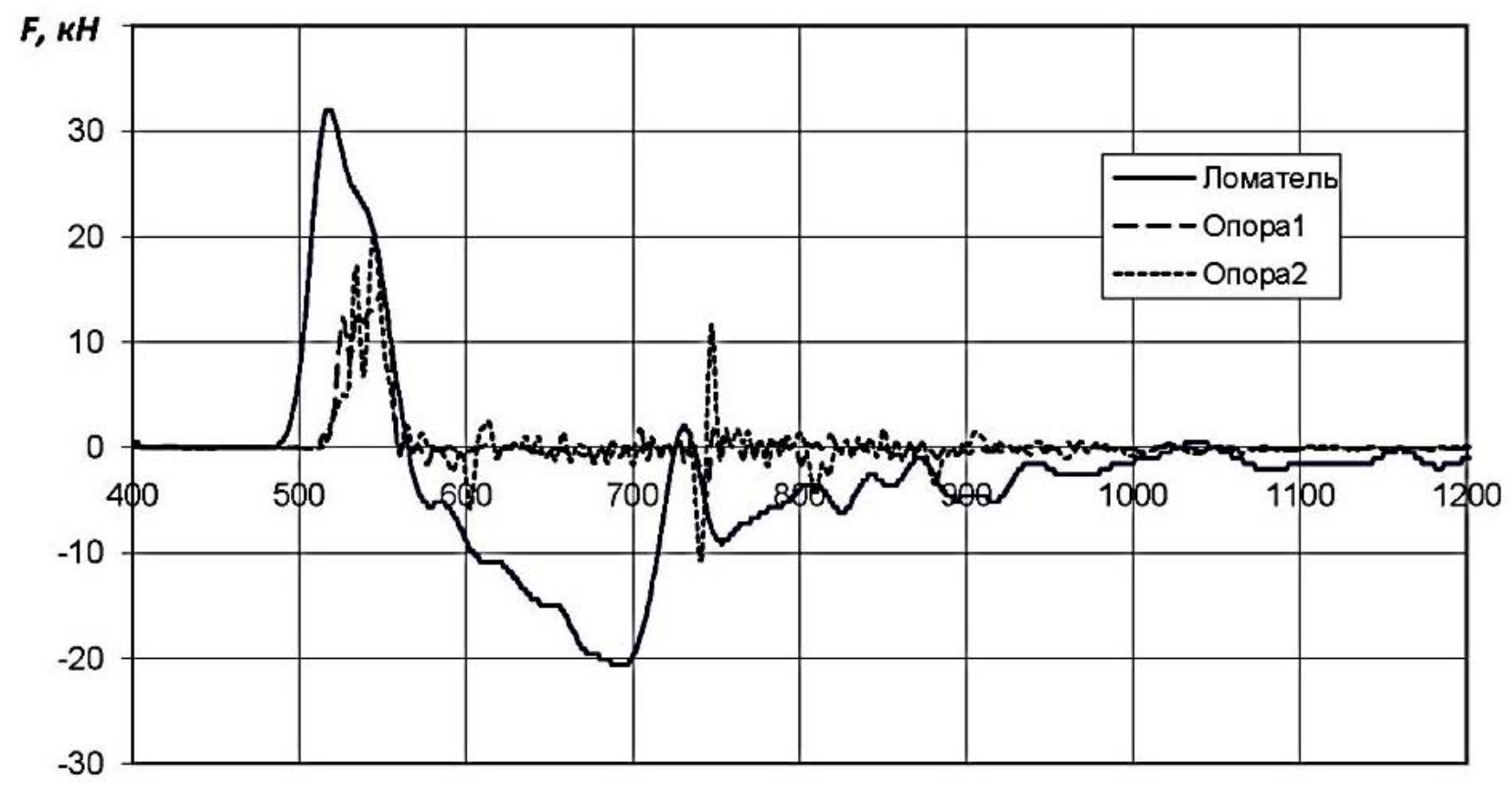

Ось X - время, масштаб - 100000 измерений в 1 с.

Рис. 2. Зависимость силы на ломателе и опорах от времени (показания трех каналов, снимаемых одновременно) для образцов из стали 45 [8]

Показатели геометрической точности, по которым оценивалось качество разделяемых заготовок, приведены в работе [2].

Фотографии заготовок из сталей с разными механическими свойствами, полученные способом трёхточечной холодной ломки изгибом при статико-динамическом нагружении, показаны на рис. 3.

Высокое качество заготовок наблюдалось при разделении стали 50ХФА (рис. 3, а). Величина отклонения траектории трещины от прямолинейности $\delta_{i}$ практически равна нулю, поверхность разрушения матовая. Области пластической деформации в зоне поверхности излома отсутствовали.

При статико-динамическом нагружении образцов из стали 30 по схеме трехточечной холодной ломки изгибом наблюдалось повышение качества заготовок по сравнению со статическим и динамическим нагружением (рис. 3,б). Величина отклонения траектории трещины в среднем составила $\delta_{i}=(1,4 \pm 0,05) \mathrm{Mм}$, на поверхности излома имелись отдельные сколы, вырывы металла, микро- и макротрещины, высота макронеровностей уменьшилась и не превышала 0,3 мм. 


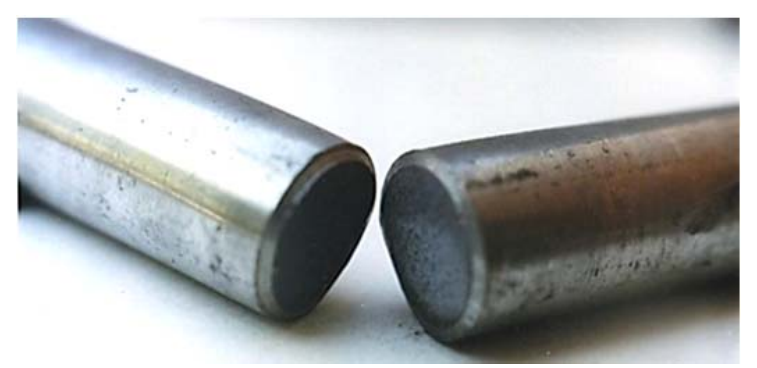

a

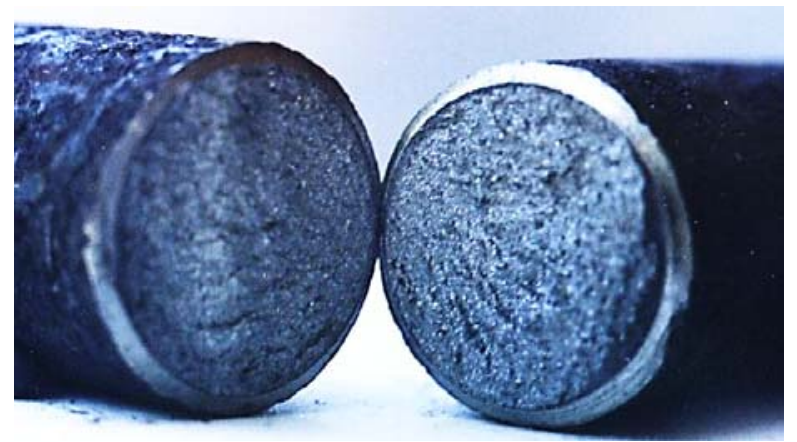

B

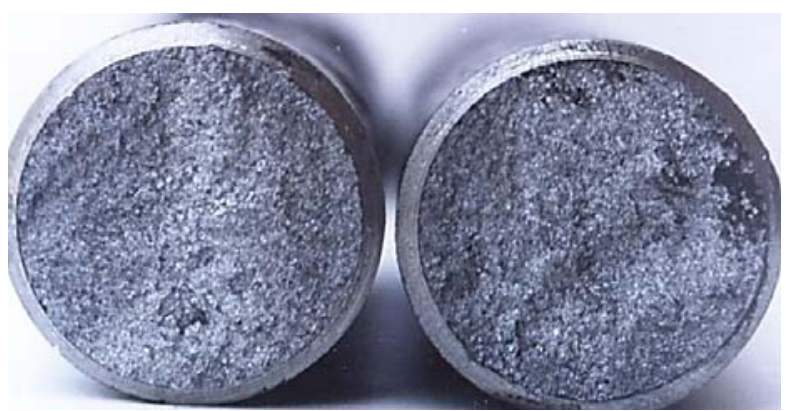

6

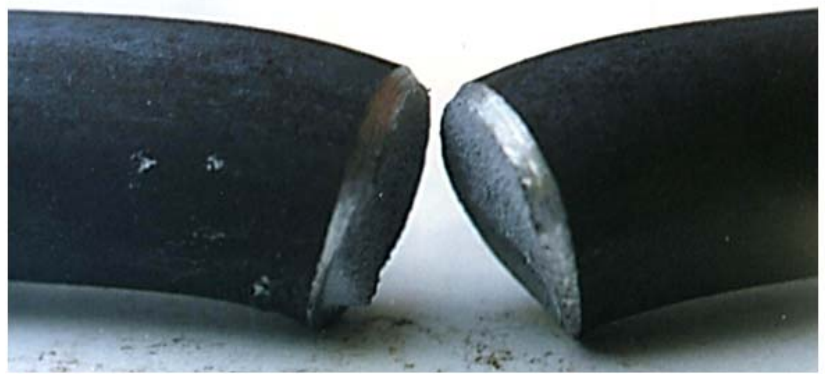

$\Gamma$

Рис. 3. Заготовки из стали (а - Сталь 50ХФА; б - Сталь 30; в - Сталь 40; г - Ст. 3), полученные способом трёхточечной холодной ломки изгибом при статико-динамическом нагружении

При статико-динамическом нагружении образцов из стали 40 также наблюдалось повышение качества разделяемых заготовок (рис. 3, в). Величина отклонения траектории трещины от прямолинейности в среднем составила $\delta_{i}=(0,8 \pm 0,05)$ мм, поверхность излома имела меньшие сколы, вырывы, макротрещины.

При статико-динамическом нагружении образцов из мягких пластичных сталей (Ст.3) разрушение происходило при больших углах изгиба половинок образцов в диапазоне $30 \ldots 35^{0}$ (рис. 3, г). Большие углы изгиба являются причиной выхода пластической деформации на поверхность образца. В результате на поверхности образцов имелись утяжки. Средние параметры геометрической точности заготовок из стали Ст. 3 при статико-динамическом нагружении имели следующие значения: утяжка продольная - 12 мм; утяжка поперечная 5 мм; $\delta_{i}=1,8$ мм; косина - 4 мм; на поверхности имелась небольшая вмятина от бойка. При этом поверхность излома не имела сколов, вырывов, макротрещин. Это объясняется тем, что при малых нагрузках на образец, трещина росла медленно и не набирала скорость, достаточную для ветвления.

Зависимость величины отклонения траектории трещины $\delta_{i}$ от величины статической нагрузки $F_{C T}$ для сталей разных групп твердости представлена на рис. 4. 


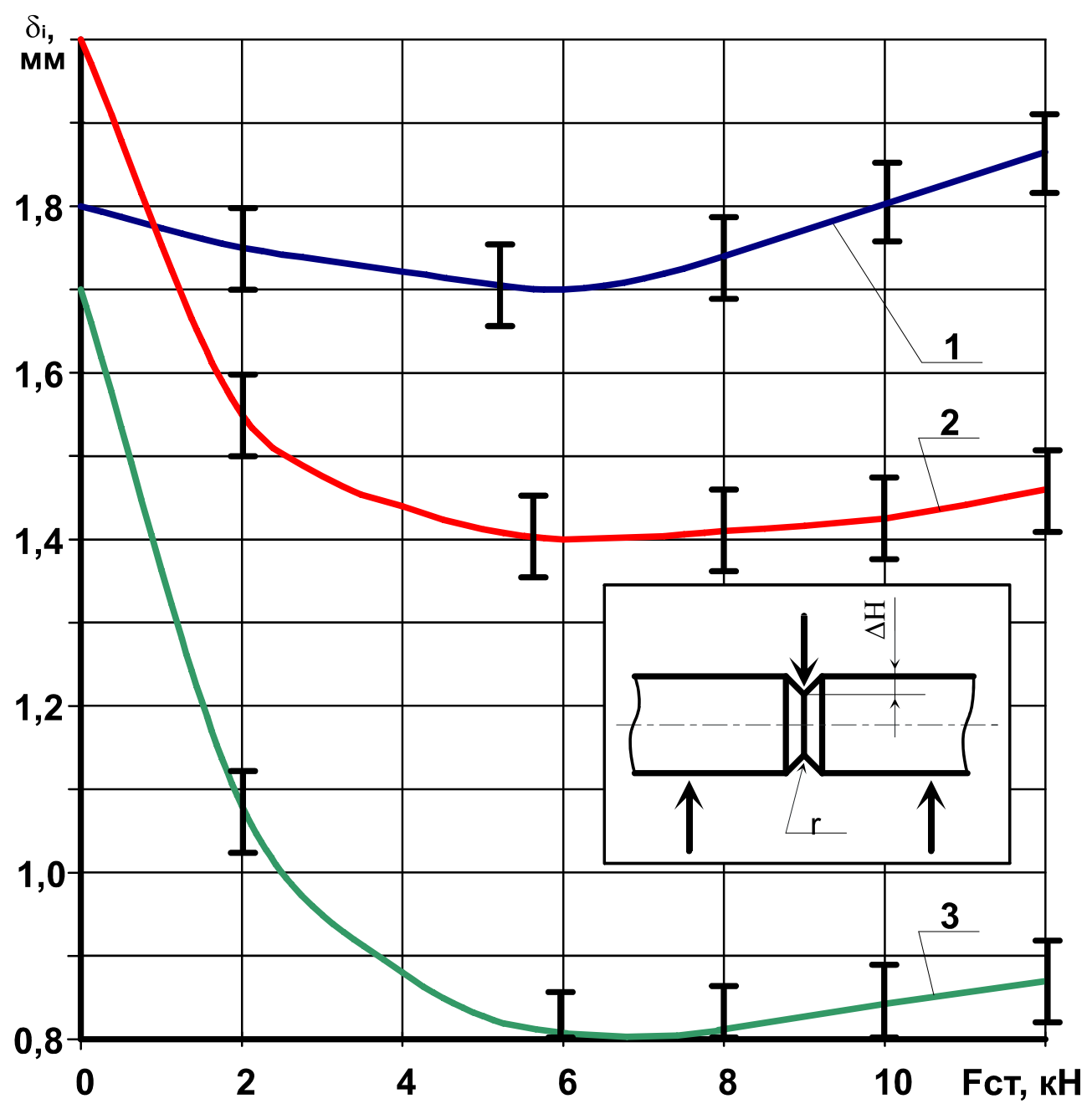

Рис. 4. Зависимость отклонения траектории трещины от величины статической нагрузки при трехточечной холодной ломке изгибом образцов на пресс-молоте:

1 - для стали Ст. 3; 2 - для стали 30; 3 - для стали 40

Анализ зависимостей $\delta_{i}=f\left(F_{C T}\right)$ показывает, что для получения заготовок высокого качества рекомендуется выбирать величину статической силы $F_{C T}$ в диапазоне $40 . .50 \%$ от силы трехточечной холодной ломки изгибом $F_{л}$. На основании анализа зависимости величины отклонения траектории трещины от значения предела прочности разделяемых образцов $\delta_{i}=f\left(\sigma_{B}\right)$ (рис. 5) установлено, что с увеличением прочности материала повышается качество получаемых заготовок.

Эксперимент в целом показал, что комбинированное статико-динамическое нагружение образцов при холодной ломке изгибом положительно влияет на качество разделяемых заготовок, что подтверждает теоретические выводы. Существенное повышение качества наблюдалось при разделении сталей средней группы твердости: величина отклонения траектории трещины $\delta_{i}$ уменьшилась в среднем на $75 \%$, по сравнению с динамическим нагружением.

На основании проведенных экспериментов установлена рекомендованная величина статической силы, которая составляет $40 . .50 \%$ от силы ломки для получения заготовок высокого качества.

На основании полученных выводов и рекомендаций разработана конструкция прессмолота с клиношарнирным механизмом с вогнутым клином (рис. 6) для разделительных операций при статико-динамическом нагружении. 


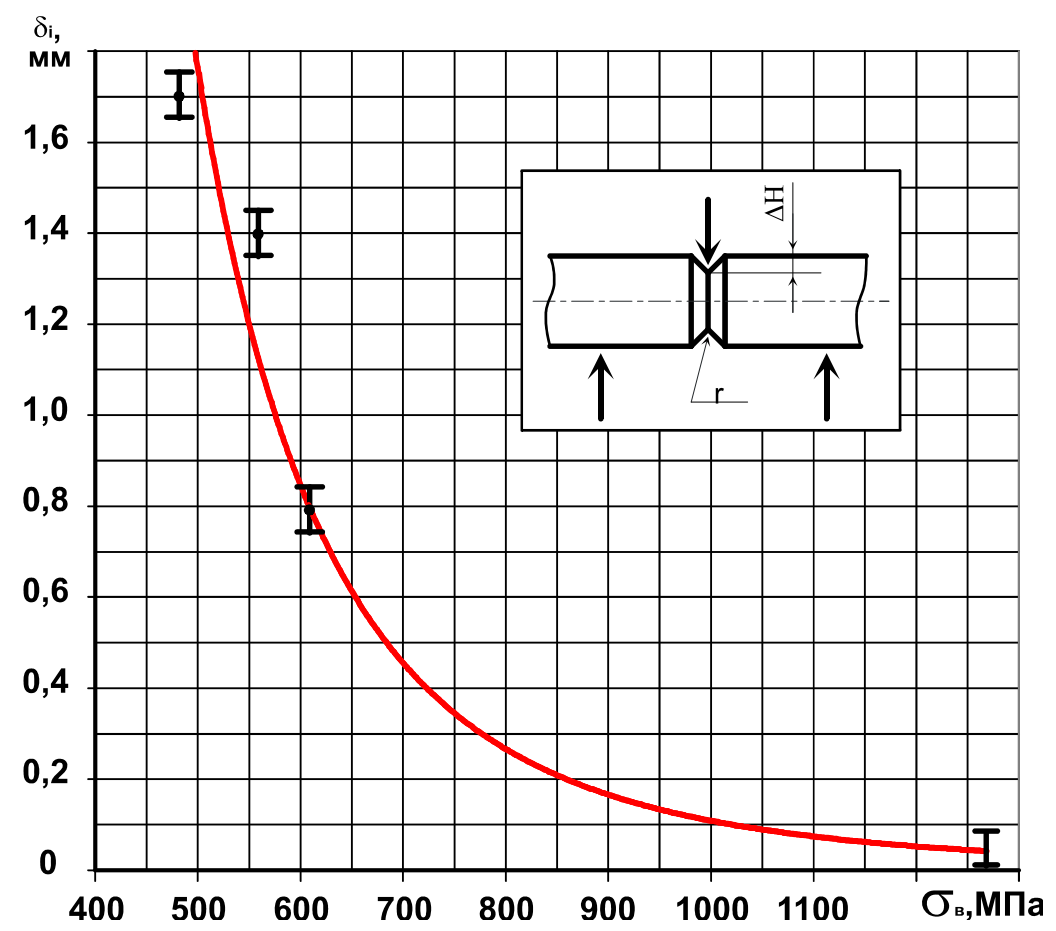

Рис. 5. Зависимость величины отклонения траектории трещины от предела прочности разделяемых материалов способом трёхточечной холодной ломки изгибом при статикодинамическом нагружении

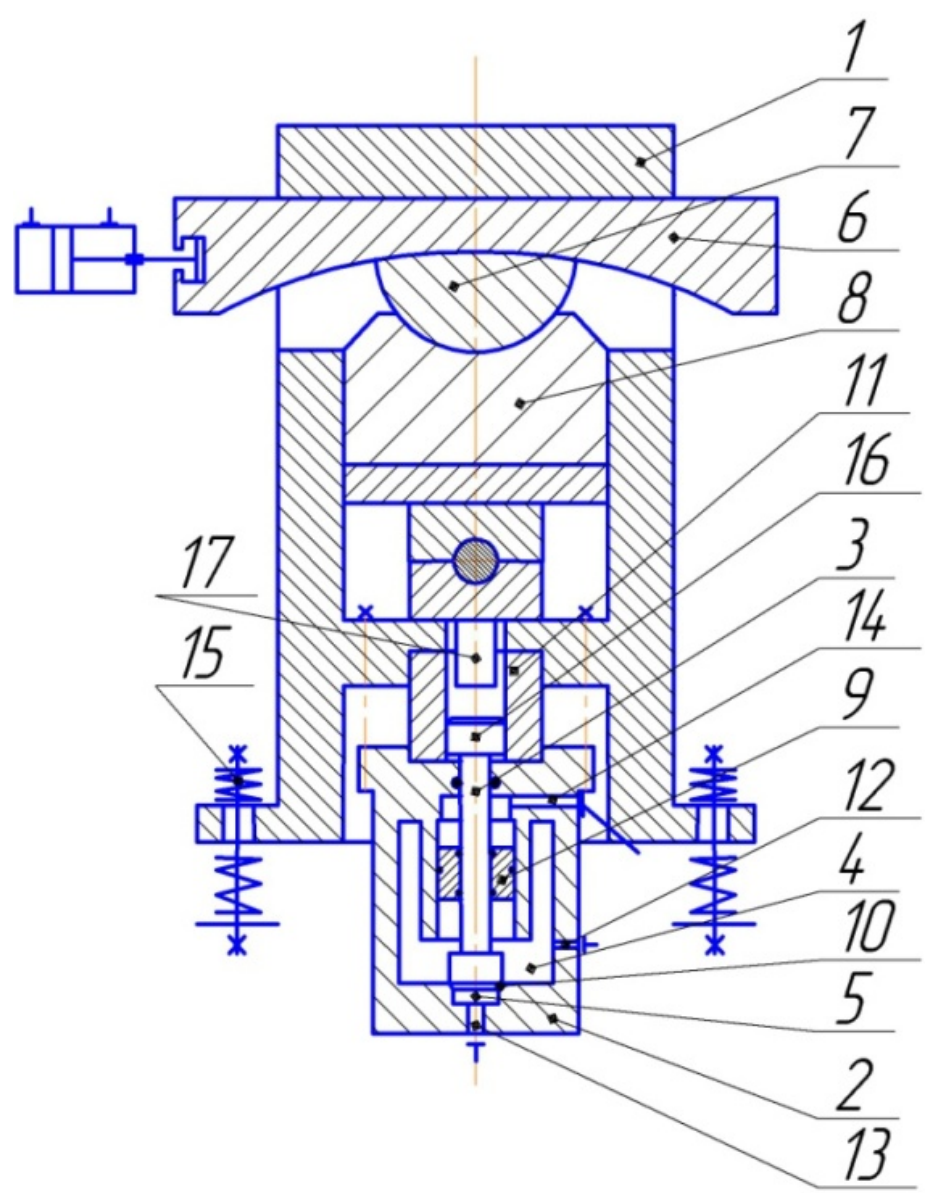

Рис. 6. Конструкция пресс-молота с клиношарнирным механизмом с вогнутым клином для разделительных операций при статико-динамическом нагружении [9] 
Пресс-молот состоит из станины 1, приводного механизма и гидроупругого цилиндра, содержащего цилиндр 2 и шток 3 , который установлен с возможностью разделения внутренней полости цилиндра 2 на полости высокого 4 и низкого 5 давления. Приводной механизм выполнен в виде клиношарнирного механизма, вогнутый клин 6 которого размещен с возможностью взаимодействия своей цилиндрической поверхностью с соответствующей выпуклой цилиндрической поверхностью шарнира 7 , который, в свою очередь, контактирует второй выпуклой цилиндрической поверхностью с вогнутой поверхностью подвижной траверсы 8, при этом шарнир 7 установлен с возможностью вращательного движения в подвижной траверсе 8. Соосно штоку 3 установлен поршень 9 в направляющих гидроупругого цилиндра. При этом торец штока 3 уплотнен относительно дна цилиндра 2 кольцевым уплотнением 10 с диаметром, большим диаметра штока 3. Цилиндр 2 центрируется, относительно станины 1, направляющей 11 и крепится винтами к столу станины. Управление цилиндром 2 осуществляется по каналам 12, 13, 14. На подвижной траверсе 8 и плите станины 1 установлено технологическое оборудование. Для снижения динамических нагрузок на фундамент, пресс-молот установлен на упругие элементы 15.

Пресс-молот работает следующим образом. В исходном положении подвижная траверса 8, вместе со штамповой оснасткой, поднята. Шток 3 с бойком 16 гидроупругого цилиндра находится в нижнем положении на кольцевом уплотнении 10. При рабочем ходе клина 6 шарнир 7, поворачиваясь на рабочий угол, перемещает вниз по направляющим подвижную траверсу 8. При этом происходит статическое нагружение проката. После набора давления в полости 4 цилиндра 2 жидкостью, подаваемой по каналу 12, поршень 9 перемещается вверх до упора и занимает исходное положение. Далее жидкость подают в полость низкого давления 5 под кольцевое уплотнение 10 по каналу 13. При этом шток 3 с бойком 16 отрывается от кольцевого уплотнения 10, разгоняется энергией гидравлической пружины и наносит удар по промежуточной проставке 17. В процессе удара происходит статико-динамическое нагружение проката и отделение заготовки. После удара и отскока бойка 16, за счет дополнительной деформации заготовки, технологическая сила на движущуюся траверсу 8 снижается или снимается полностью. Под действием усилия привода, клин 6, шарнир 7 и траверса 8 занимают исходное положение. Жидкость под давлением по каналу 14 подается в полость над поршнем 9. Поршень 9 перемещается вниз и возвращает шток 3 в исходное положение на кольцевое уплотнение 10. Цикл работы пресс-молота повторяется.

Предложенная конструкция пресс-молота значительно расширяет технологические возможности оборудования и обеспечивает высокое качество разделяемых заготовок.

\section{ВЫВОДЫ}

Комбинированное статико-динамическое нагружение образцов при холодной ломке изгибом положительно влияет на качество разделяемых заготовок. Существенное повышение качества наблюдалось при разделении сталей средней группы твердости: величина отклонения траектории трещины уменьшилась в среднем на $75 \%$ по сравнению с динамическим нагружением.

Даны рекомендации по величина статической силы при статико-динамической ломке сортового проката изгибом. Рекомендованная величина статической силы составляет (40...50) \% от силы ломки для получения заготовок высокого качества.

На основании полученных результатов разработана конструкция пресс-молота с клиношарнирным механизмом с вогнутым клином для разделительных операций при статико-динамическом нагружении.

\section{СПИСОК ИСПОЛЬЗОВАННОЙ ЛИТЕРАТУРЫ}

1. Финкель В. М. Холодная ломка проката / В. М. Финкель, Ю. И. Головин, Г. Б. Родюков. - М. : Металлургия, 1982. - 192 c.

2. Соловияов С. С. Безотходная разрезка сортового проката в штампах / С. С. Соловичов. - М. : Машиностроение, 1985. - 176 c. 
3. Карнаух С. Г. Совершенствование безотходных энергосберегающих способов разделения сортового металлопроката и оборудования для получения заготовок высокого качества : дис. ... канд. техн. наук : 05.03.05 / Карнаух Сергей Григорьевич. - Краматорск, 1999. - 221 с.

4. Карнаух С. Г. Совершенствование безотходных способов разделения сортового проката и оборудования для получения заготовок высокого качества : монография / С. Г. Карнаух. - Краматорск : ДГМА, 2010. - 196 с.

5. Карнаух С. Г. Совершенствование оборудования для разделения сортового проката на мерные заготовки / С. Г. Карнаух // Обработка материалов давленим : сб. науч. трудов. - Краматорск : ДГМА, 2017. № 2 (45). - C. 154-160.

6. Карнаух С. Г. Разработка и исследование оборудования для разделения сортового проката на мерные заготовки / С. Г. Карнаух // Обработка материалов давлением : сб. науч. трудов. - Краматорск : ДГМА, 2017. - № 1 (44). - C. 222-228.

7. Карнаух С. Г. Исследование прочесса статико-динамического нагружения заготовок по схеме трехточечной холодной ломки изгибом на пресс-молотах / С. Г. Карнаух // Кузнечно-итамповочное производство. Обработка материалов давлением. - 2001. - Bып. № 2. - C. 8-12.

8. Karnaukh, S. G. Research of the influence of deformation speed on energy and power adjectives of the process of three-point cold bend breaking and on alignment integrity of raw parts / S. G. Karnaukh, D. S. Karnaukh // Metallurgical and Mining Industry. - 2011. - № 3, Vol. 3 - C. 107-114.

9. Патент на корисну модель 111267 Украӥна, МПК (2016.01) В 30 В 1/00. Прес-молот з клиношарнірним механізмом з увігнутим клином / КарнаухС. Г., Карнаух Д. С., Чоста Н. В., Коляденко А. В. Заявл. 04.04.2016 ; опубл. 10.11.2016, Бюл. № 21/2016. - 4 с.

\section{REFERENCES} 1982. $-192 \mathrm{~s}$

1. Finkel' V. M. Holodnaja lomka prokata / V. M. Finkel', Ju. I. Golovin, G. B. Rodjukov. - M. : Metal-lurgija,

2. Colovcov S. S. Bezothodnaja razrezka sortovogo prokata v shtampah / S. S. Colovcov. - M. : Mashinostroenie, 1985. - $176 \mathrm{~s}$.

3. Karnauh S. G. Sovershenstvovanie bezothodnyh jenergosberegajushhih sposobov razdelenija sortovogo metalloprokata i oborudovanija dlja poluchenija zagotovok vysokogo kachestva : dis. ... kand. tehn. nauk : 05.03.05 / Karnauh Sergej Grigor'evich. - Kramatorsk, 1999. - 221 s.

4. Karnauh S. G. Sovershenstvovanie bezothodnyh sposobov razdelenija sortovogo prokata i oborudovanija dlja poluchenija zagotovok vysokogo kachestva : monografija / S. G. Karnauh. - Kramatorsk: DGMA, 2010. - 196 s.

5. Karnauh S. G. Sovershenstvovanie oborudovanija dlja razdelenija sortovogo prokata na mernye zagotovki / S. G. Karnauh // Obrabotka materialov davlenim : sb. nauch. trudov. - Kramatorsk : DGMA, 2017. - № 2 (45). S. $154-160$.

6. Karnauh S. G. Razrabotka i issledovanie oborudovanija dlja razdelenija sortovogo prokata na mernye zagotovki / S. G. Karnauh // Obrabotka materialov davleniem : sb. nauch. trudov. - Kramatorsk : DGMA, 2017. № 1 (44). - S. 222-228.

7. Karnauh S. G. Issledovanie processa statiko dinamicheskogo nagruzhenija zagotovok po sheme trehtochechnoj holodnoj lomki izgibom na press-molotah / S. G. Karnauh // Kuznechno-shtampovochnoe proizvod-stvo. Obrabotka materialov davleniem. - 2001. - Vyp. № 2. - S. 812.

8. Karnaukh, S. G. Research of the influence of deformation speed on energy and power adjectives of the process of three-point cold bend breaking and on alignment integrity of raw parts / S. G. Karnaukh, D. S. Karnaukh // Metallurgical and Mining Industry. - 2011. - № 3, Vol. 3 - C. 107-114.

9. Patent na korisnu model' 111267 Ukraïna, MPK (2016.01) B 30 B 1/00. Pres-molot z klinosharnir-nim mehanizmom z uvignutim klinom / Karnauh S. G., Karnauh D. S., Chosta N. V., Koljadenko A. V. - Zajavl. 04.04.2016 ; opubl. 10.11.2016, Bjul. № 21/2016. - 4 s.

Карнаух С. Г. - канд. техн. наук, доцент, зав. кафедры ОПМ ДГМА.

ДГМА - Донбасская государственная машиностроительная академия, г. Краматорск.

E-mail: sergey.karnauh@dgma.donetsk.ua 